\title{
Estimation of the Recreational Value of Koohgol Resort in Sisakht City Using the Contingent Valuation Method
}

\author{
Iman Najafi \\ Doctoral student of Department of agriculture Economics, Science and Research Branch \\ Islamic Azad University, Tehran, Iran

\section{Seyyed Mohammad Kazem Etemad}

\author{
Master student of Department of Economics, Yasouj Branch, Islamic Azad University, Yasouj, Iran
}

\section{Doi:10.5901/mjss.2015.v6n6s6p25}

\begin{abstract}
Koohgol is one of the beautiful and spectacular scenery in Kohgiluyeh and Boyer-Ahmad Province in the north-east of Sisakht City and is located about 8 kilometers from it and as a recreational resort, it welcomes many tourists every year. The goal of this study is estimation of the willingness to pay of the visitors of Koohgol resort in Sisakht City. The required statistics and data were collected through the completion of 229 Double Dichotomous Choice (DDC) questionnaires by the visitors of the aforementioned resort in spring and summer of 2013. In order to estimate the rate of people's willingness to pay, the contingent valuation method was used. In order to investigate the factors effective in people's willingness to pay, the logit model based on maximum likelihood was estimated. The results showed that the variables of suggestion and the household size have a significant and negative effect and the variables of income and education have a significant and positive effect on the possibility of willingness to pay. Average willingness to pay per person to enter the Koohgol resort in Sisakht City has been determined as 1998.5 rials. Also, the average household size is 5.56 individuals and every person is willing to pay an average of 1998.5 rials to enter the resort. From the average household size, average willingness to pay, and from its multiplication by the number 12 , the average annual recreational value per family for visiting the Koohgol resort in Sisakht City was obtained as 133339.92 rials.
\end{abstract}

Keywords: contingent valuation, recreational value, logit model, willingness to pay, Koohgol resort, Sisakht City

\section{Introduction}

Products or services are valuable only when humans valuate them directly or indirectly. Value is measured based on give-and-take relations and deals and is therefore relative. For this purpose, money is usually used as a unit of account and the total value of the society is the sum of individual values (Feror, 2007). Economic valuation compares the benefits of the use of resources with the costs. The costs are in fact the lost benefits. Economic valuation is the process of determining the value of environmental goods and services. This is done in order to achieve a single output. In economic valuation of environmental goods and services, the inventory of goods and services (natural resources) in the environment and change in the performance of each of the environmental goods and services (natural resources) are valuated (Suparmoco 2008). Natural resources and decision-making are two issues affecting each other. Decisions, particularly decisions in the economic sphere, usually lead to negative consequences in the area of natural resources. Also, changes in the range of natural resources have economic consequences. As much of the natural ecosystems services are not traded in the market and do not have a price, the process of destruction of these resources is continuing considerably (Moradi, 2008). Population growth, expansion of the cities and increasing migration of villagers to cities have brought about problems, such as imbalance in supply and demand, for recreational and welfare centers in the cities. This imbalance has caused people to rush into nature and natural resorts and therefore, careful planning for utilization of these resources are required for conservation of these natural resources. As natural resources can't be exchanged in the market, it is necessary that their value be determined through proper methods. In order to prevent the destruction of natural resources, consumers must consider these resources as economic goods and this requires the valuation of these resources and charging fees to beneficiaries so that from the resulting revenues, the costs imposed on these natural resorts can be compensated and the required investment be made to restore and maintain them. Koohgol Lake is one of the beautiful and spectacular sceneries in Kohgiluyeh and Boyer-Ahmad Province in the north-east of Sisakht City and is located about 8 kilometers from it and like the blue pearl of a ring surrounded by yellow narcissus flowers, violets and 
lilies and also beautiful pastures, it is one of the unparalleled tourist attractions which annually welcomes many domestic and foreign visitors in spring and summer. This lake, which is located on the mountain range near the summit of Koohgol Dena, has asphalted access road and some minutes of hiking in this beautiful and natural tourist attraction can be seen and utilized. Based on what has been mentioned above, it is necessary that the required plans be carried out for conservation and maintenance of this natural resort. This study is aimed at the estimation of willingness to pay of the visitors of Koohgol resort in Sisakht City. Regarding the valuation of natural resources and recreational centers, numerous studies have been conducted some of which will be mentioned.

Karimzadegan et al. (2000) conducted a study by means of the contingent valuation method through the model for expansion of linear cost system in order to determine the cost of environmental benefits (market services) of the planted forest of Garbayegan Fasa in Fars Province. In this study, the value of major non-market services, including the value of regulation of climactic conditions, value of soil erosion control and stabilization of sand dunes and the value of creation of habitat and wildlife sanctuary were estimated to equal 32.2 billion rials, 29.6 billion rials and 25.9 billion rials respectively. Amirnezhad (2005) used the contingent valuation method for estimation of the conservation value of the forests in the north of the country and collected the required data through competition of the questionnaire. In order to estimate the individuals' willingness to pay, the logit model has been used and the given results indicate that the families' willingness to pay for conservation of the forests in the north equals 12848 rials per month. The annual conservation value per hectare of these forests has been estimated to be about one million and based on this, conservation value for the whole forests in the north was estimated as 1915.2 billion rials. Aminezhad et al. (2006) in a study investigated the conservation and recreational values of Sisangan forest park in Noshahr by means of people's willingness to pay. The average willingness to pay for the conservation and recreational value was estimated to be 6365 rials for every family and 2477 rials for every visitor respectively. The annual conservation and recreational value of this park was estimated to be 2.8 and 2.5 million rials per hectare respectively.

Peron (2007) has investigated the economic valuation of Hara forest in Hormozgan Province. In this study, the conservation value and indirect market value of the aforementioned forest were calculated by means of the contingent valuation method and DDC questionnaire. The individuals' average willingness to pay for conservation of Hara forest was calculated as 450000 rials per person. The non-market value of Hara forest was calculated by means of the individuals' average willingness to pay for conservation of the forest and this number has been equivalent to 15144215 rials per hectare. Chabokrou and Bagherpour (2008), by means of the individuals' willingness to pay, estimated the conservation value of the Bonab forest park in Arsanjan and estimated the level of willingness to pay of families for conservation of Bonab park as 7992 rials per month and the annual conservation value of every family for this park as 392247 rials. Manafi Molayusefi \& Hayati (2010), by means of the contingent valuation method, estimated the average willingness to pay for the recreational use of Maharlou Lake of Shiraz as 3392 rials and the annual recreational value of this lake as 1187.2 million rials. Sameti et al. (2012), by means of the contingent valuation method, tried to valuate Nazhvan forest park in Isfahan. The individuals' average willingness to pay for the recreational value of the aforementioned forest park was estimated to be 8983.702 rials per person per month. Moradi et al. (2012) in a study estimated the recreational value of Yasuj forest park. In order to determine the recreational value and measure people's willingness to pay, contingent valuation method and DDC questionnaire were used. The results showed that $86.9 \%$ of the people under study in this research were willing to pay an amount for creational use of the aforementioned forest park. The average willingness to pay for every visitor was 992.73 rials and the total recreational value was estimated as 7.43 billion rials.

Tirvaynin (2001) estimated the level of willingness to pay for a two-hour trip to several urban forests in Finland by means of the contingent valuation method to be within the range of 1.6 and 2.9 euros. Lee \& Han (2002), in a study in South Korea, estimated the recreational value of five national parks in the contingent valuation method as an average of 10.54 dollars per family per year. Visintien (2004), in a study, examined natural landscapes in Slovenia such as Brada vineyards. In order to estimate the individuals' willingness to pay, he used the probit model and estimated this amount for the residents and the visitors as 239 and 38 euros per family per year respectively. Gurluk (2006), in a study, by means of contingent valuation method, estimated the ecosystems services value in Barca state of turkey as 67.44 dollars per year per family. Loomis et al. (2007), in a study calculated the level of recreational WTP by means of CVM method and through questionnaire completion from the visitors of Caribbean national parks in Porto Rico and this amount was determined as 109 dollars for each trip; also, the variable of price suggestion, at the $99 \%$ level, and the variable of the road, at the $95 \%$ level, were significant with negative coefficient. Verbic \& Slabe-Erker (2008), in a study, by an econometric analysis of willingness to pay for sustainable development, investigated Velji Portouk landscapes and scenery in Slovenia. In the estimated model, for determination of the factors effective in willingness to pay, the variables of age, sex and place of residence did not have a significant effect on the variable of willingness to pay. Also, the accountable household size did not have a significant effect on the willingness to pay. The value of the willingness to pay 
obtained by means of explanatory variables equals 474.8 currencies. Gurluk \& Rib (2008) have used the travel cost method for estimation of the recreational value of the location for conservation of the birds in Kazsenti national park in Turkey. The recreational value of this park was estimated as 10332074 dollars per year, which is higher than the annual and operating investment expenditures of this park. Kin, Veng \& Cho (2007) in a study estimated the use value of the World Cultural Heritage forest park. In this study, contingent valuation method was used. They used DDC questionnaire 4 which had 10 suggested prices. In this study, the logit model was estimated for two linear and logarithmic modes. The obtained level of willingness to pay was calculated as 5.7 dollars for the linear method and 6 dollars for the logarithmic method. Key Li \& Majd (2007) studied the Demilitarize (DMZ) region in South Korea. Two goals were considered in this study; the first goal of estimation of DMZ conservation value and the second goal of people's willingness to pay for its maintenance were investigated through contingent valuation method. The best estimate of willingness to pay was an equivalent of 16.74 dollars per unit of capital. The average value of survival was estimated between 264 and 602 dollars. In the study that was carried out by Lehtonen et al. (2003), the value of conservation plans of the forests in the south was analyzed. They used the two CVM and CE methods. Based on the given results, in the CVM method, $74 \%$ of the residents were willing to pay an amount so that the forests could be conserved but $16 \%$ of the people were not willing to pay for conservation of the forest. Based on CE method, $14 \%$ of the selected residents had a willingness to pay equal to zero. The average willingness to pay for the increase of conservation of forests was estimated between 60 and 223 dollars per family per year.

\section{Research Methodology}

In this study, in order to estimate the recreational value of Koohgol resort and lake in Sisakht City of Kohgiluyeh and Boyer-Ahmad Province, the contingent valuation method has been used. From among the available methods, the contingent valuation method is the most important and the most appropriate method. The contingent valuation method is usually centered on the estimated value of the scenario for special environmental changes. Investigation of contingent valuation starts with an explanation on the change in environmental goods or services. It subsequently poses questions to people in order to determine how much they are ready to pay for changes. For instance, analysts might ask the taxpayers whether they will agree to the increase of costs in their water bills for conservation of upstream water resources or not. In this method, the responders must be well aware of the nature of that which is valuated and must also have an appropriate understanding of the level of acceptance of balance between the changes of environmental features and their income (Lee et al., 2010). This method is in general used as one of the standard and flexible tools for measurement of non-consumptive values and non-market consumptive values of environmental resources. The contingent valuation method tries to determine people's willingness to pay under certain hypothetical market scenarios, and this method is based on the research approach and investigation for valuation of non-market environmental goods and services. This approach requires hypothetical construction or market stimulation through the questionnaire in which responders answer the questions related to the level of their willingness to pay or acceptance with regard to special environmental changes (Oftak, 2006). In this study, in order to measure the visitors' level of willingness to pay in contingent valuation, DDC questionnaire has been used. In this questionnaire, suggested prices are considered and the individuals are asked to determine their responses with "yes" or "no". In this stage, lower, middle and higher suggested prices have been stated. These prices are 5000, 10000 and 15000 rials respectively. The questions are ordered in such a way that first the middle price is asked; in case the answer is positive, a higher price is suggested and if the answer is negative, a lower suggested price is presented. In order to determine the model for measurement of the willingness to pay, it has been assumed that the individual accepts the suggested price for determination of the recreational value of the resort based on maximization of their utility, under the following conditions (Lee \& Han, 2002; Hanman, 1994).

$$
U(1, Y-A ; S)+\varepsilon_{1} \geq U(0, Y ; S)+\varepsilon_{0}
$$

$U$ is an indirect utility which the individual obtains from the resort. $Y$ and $A$ are respectively the individual's income and the suggested price and $S$ refers to the other socioeconomic features that are influenced by personal taste. ${ }^{\varepsilon_{0}}$ and ${ }^{\varepsilon_{1}}$ are random variables with the average of zero that have been equally and independently distributed. The utility difference $(\Delta \mathrm{U})$ can be described as below:

$$
\Delta U=(1, Y-A ; S)-U(0, Y ; S)+\left(\varepsilon_{1}-\varepsilon_{0}\right)
$$

The double questionnaire format in the contingent valuation method has a dependent variable with double choice which requires a selected qualitative model. Logit and probit models are usually used for qualitative selection methods (Lehtonen et al., 2003; Lee \& Han, 2002). In this study, the logit model has been used for simplicity for investigation of the 
impact of various explanatory variables on the level of WTP of individuals and visitors for determination of the conservation value. The regression model used in this study is as follows:

$$
Y=\alpha+\sum \beta_{i} X_{i}
$$

In which $Y$ is the dependent variable and shows the willingness to pay of the visitors of Koohgol resort in Sisakht City. If the person is willing to pay an amount for visiting and staying in this recreational resort, $y=1$ and if the person will not be willing to pay, $y=0$ will be considered. The vector $X$ is also representative of explanatory variables of the model including age, the individual's income, the household size and education.

The possibility $\left(p_{i}\right)$ that the individual might accept one of the suggestions (A), is expressed as below based on the logit model (Lee \& Han, 2002; Howarth \& Farber, 2002; Hanman, 1984):

$$
P_{i}=F_{\eta}(\Delta U)=\frac{1}{1+\exp (-\Delta U)}=\frac{1}{1+\exp \{-(\alpha-\beta A+\gamma Y+\theta S)\}}
$$

In which, $F_{\eta}(\Delta \mathrm{U})$ is a cumulative distribution function with a standard logistic difference and includes some of the socioeconomic variables in this study. $\gamma, \beta \& \theta$ are estimated coefficients and it is expected that: $\gamma>0, \quad \beta \leq 0$ \& $\theta>0$ (Lee \& Han, 2002; Hanman, 1994).

The logit model parameters are estimated by means of the maximum likelihood method which is the most common technique for estimation of the logit model (Lehtonen, 2003; Lee \& Han, 2002; Judej et al., 1998). Subsequently, by numerical integration within the range of zero to the highest suggestion $(A)$, the level of WTP is calculated as below:

$$
E(W T P)=\int_{0}^{\operatorname{Max}} A F_{\eta}(\Delta U) d A=\int_{0}^{\operatorname{Max}}\left(\frac{1}{1+\exp \left\{-\left(\alpha^{*}+\beta A\right)\right\}}\right) d A
$$

And in the above equation, E (WTP) is the expected value of WTP and $\alpha^{*}$ is the adjusted intercept which is added by means of the socioeconomic statement to the main intercept statement ${ }^{(\alpha)}\left[\alpha^{*}=(\alpha+\gamma Y+\theta S)\right\rfloor$.

\section{Results and Discussion}

The required statistics and data for calculation of the recreational value of Koohgol resort in Sisakht City were collected through the completion of 256 DDC questionnaires by calling on the visitors of Koohgol resort in Sisakht City by means of the simple random sampling method. Eventually, 27 questionnaires that had flawed and incomplete data were excluded and the analyses were done by the 229 remaining questionnaires that had full data. The aforementioned questionnaires have two overall parts: the first part includes personal and social data and the questions on willingness to pay are included in the second part. In this part, three suggested prices to visitors- 5000, 10000 and 150000 rials- were considered dependently and firstly the price of 10000 rials was suggested thus: Koohgol resort in Sisakht City has created some facilities for your recreation and rest; are you willing to pay 10000 rials from your monthly income as the entrance fee for each of your family members to use this resort? In case this price was accepted by the visitor, in the next step, a price of 150000 rials was suggested and in case of lack of acceptance, a lower price was suggested. table (1):

The descriptive statistics related to socioeconomic features of the visitors have been presented in the sample of

Table 1- Descriptive statistics of important social variables of the sample visitors

\begin{tabular}{|c|c|c|c|l|}
\hline Max. & Min. & Standard deviation & Average & Variables \\
\hline 70 & 25 & $10 / 26$ & $36 / 53$ & Age of responders (years) \\
\hline 20 & 6 & $3 / 22$ & $16 / 16$ & Number of education years \\
\hline 8 & 2 & $2 / 46$ & $5 / 56$ & Size of every household \\
\hline
\end{tabular}

Source: research findings

Table (2) has been completed based on the data inserted in the questionnaires. This table shows the individuals' willingness to pay with regard to the suggested prices. 
Table 2 - The responding status of the individuals in the sample and the suggested prices for entry into Koohgol resort in Sisakht City

\begin{tabular}{|c|c|c|c|c|}
\hline Third suggestion (15000 rials) & Second suggestion (5000 rials) & \begin{tabular}{|l|}
$\begin{array}{l}\text { First suggestion } \\
(10000 \text { rials })\end{array}$ \\
\end{tabular} & & $\begin{array}{l}\text { Suggested price } \\
\text { State of acceptance }\end{array}$ \\
\hline 58 & 69 & 126 & Number & \multirow{2}{*}{ Acceptance of the suggested price } \\
\hline $25 / 32$ & $30 / 13$ & $55 / 02$ & Percentage & \\
\hline 68 & 34 & 103 & Number & \multirow{2}{*}{ Lack of acceptance of the suggested price } \\
\hline $29 / 70$ & $14 / 84$ & $44 / 97$ & Percentage & \\
\hline 126 & 103 & 229 & Number & \multirow{2}{*}{ Total } \\
\hline $55 / 02$ & $44 / 97$ & 100 & Percentage & \\
\hline
\end{tabular}

Source: research findings

By the proposition of the first suggestion (10000 rials), 126 visitors in the sample accepted it and 103 visitors didn't accept it; in other words, they were not willing to pay the fee (10000 rials) for each of their family members for entry into the resort for resting and recreation. The people that did not accept the first suggestion were placed in the lower suggestion group (5000 rials). In encountering this suggestion, 34 responders did not accept it and were not willing to pay and 69 responders accepted it. A group of the visitors that accepted the first suggestion (10000 rials) were faced with the third suggestion (15000 rials); 58 of them accepted this suggestion and 68 others rejected it. From among the people that accepted the 5000 rial suggestion, 43 of them stated their maximum willingness to pay up to 8500 rials. From among the responders that had accepted the 10000 rial suggestion but had rejected the 15000 rial price, 41 individuals stated their maximum willingness to pay up to 1300 rials. From among the 58 responders that accepted the 15000 rial suggestion, 30 individuals stated their maximum willingness to pay up to 17000 rials, 25 individuals up to 18000 rials and 3 individuals up to 20000 rials.

As mentioned before, for estimation of the willingness to pay and determination of the factors effective in WTP, the logit model has been used. The dependent variable is the variable of willingness to pay which chooses the values zero and one. The independent variables in this model include the level of suggestion, age, sex, income, education and household size, and from among the independent variables, the variable of age is dummy variable and the variable of education is ordinal variable. The given results of estimation of the logit model by means of the maximum likelihood method, including estimated coefficients, t-statistic, significance level, elasticity and good fitness criterion, for determination of the recreational value of the Koohgol resort in Sisakht City, have been shown in table (3):

Table 3 - The results of the logit model for estimation of the recreational value of Koohgol resort

\begin{tabular}{|c|c|c|c|l|}
\hline Change of possibility (elasticity) & Significance level & T-statistic value & Estimated coefficients & Variables \\
\hline$-0 / 0426$ & $0 / 1587$ & $-0 / 8761$ & $-0 / 2223$ & Fixed coefficient \\
\hline$-0 / 0051$ & $0 / 0011$ & $-3 / 652$ & $-0 / 3845$ & Suggestion \\
\hline $0 / 0265$ & $0 / 0016$ & $3 / 164$ & $0 / 8985$ & Income \\
\hline$-0 / 3839$ & $0 / 4256$ & $-0 / 765$ & $-0 / 3109$ & Age \\
\hline $0 / 0254$ & $0 / 0125$ & $2 / 564$ & $0 / 4896$ & Education \\
\hline$-0 / 0361$ & $0 / 0659$ & $-1 / 911$ & $-0 / 2815$ & Household size \\
\hline$-0 / 4265$ & $0 / 2564$ & $-1 / 5692$ & $-0 / 2634$ & Sex \\
\hline
\end{tabular}

Source: research findings

The data available in table (3) show that the variables of suggestion and income, and the variable of education have become significant at the levels of $1 \%$ and $5 \%$ respectively. Also, the variable of household size has shown a significant effect at the $10 \%$ level. The variables of age and sex have not had a significant effect on the acceptance of the suggested price.

The level of estimated coefficient for the variable of suggestion is $(-0.3845)$. This indicates that under the scenario of hypothetical market, if the suggested price increases, the possibility of positive response in willingness to pay for entry into the resort decreases and vice versa. The level of change in possibility (elasticity) for this variable equals $(-0.0051)$. This shows that with the increase by one percent in the suggested price, the possibility of the positive response in willingness to pay for entry into the resort and rest decreases by 0.0051 .

The estimated coefficient of the variable of income equals 0.8985 the sign of which corresponds to what has been 
expected. In other words, the relationship between income and possibility of positive response in the individuals' willingness to pay is positive and with the increase of income, the individuals' willingness to pay for the recreational use of the considered resort increases. The level of calculated elasticity shows that the increase by one percent of income increases the possibility for acceptance of the suggested price for the recreational use by $0.0265 \%$. The coefficient of the variable of level of education has been obtained as 0.4896 . This indicates that higher level of education leads to the increase of positive response in willingness to pay. Based on the calculated elasticity of the variable of education, with the increase of the level of education, the possibility of positive response in willingness to pay for entry into the resort and resting increases by (0.0254) percent. The estimated coefficient of the variable of household size equals $(-0.2815)$ and shows the inverse relationship between the household size and the willingness to pay; and with the increase of the household size, the visitors' willingness to pay for the recreational use of the resort decreases. The calculated elasticity for the variable of household size shows that with the increase by one percent of the household size, the possibility of acceptance of the suggested price will decrease by $(0.0361)$ percent.

Mac Fowden coefficient of determination has been calculated as 0.43 and shows that the changes of the dependent variable have been properly explained by the independent variables of the model. The percentage of correct prediction has been estimated as $82.5 \%$. Accordingly, the estimated model predicts a high rate of the dependent values in terms of the explanatory variables. More precisely, about $82 \%$ of the responders had accurately allocated the predicted "yes" or "no" willingness to pay by presentation of a completely appropriate ratio with the data. For calculation of the recreational value of the Koohgol resort in Sisakht City, the average expected value of WTP has been used and through numerical integration within the range of zero to the maximum suggestion, it is calculated as below:

$$
W T P=\int_{0}^{20000} \frac{1}{1+e^{\{(0 / 31-0 / 3845 A)\}}} d A=1998 / 5
$$

Based on the above calculation, the average willingness to pay per person for entry into the recreational resort of Koohgol in Sisakht City has been determined as 1998.5\%. Based on the average household size in table (1) which is 5.56 individuals and as every individual is willing to pay an average of 1998.5 rials for entry into the resort, from the outcome of the average household size, the average willingness to pay and its multiplication by the number 12 , the average annual recreational value per family for visiting the Koohgol resort in Sisakht City is obtained as 133339.92 rials.

\section{Summary and Suggestions}

In order to calculate the recreational value of Koohgol resort in Sisakht City, the contingent valuation method was used. The required data were collected through 229 DDC questionnaires. The suggested prices as the entrance fee for the considered resort have been 5000, 10000 and 15000 rials. In order to measure the level of willingness to pay of the society members and determine the factors effective in this willingness to pay, the logit regression model has been used and also the parameters of this model were estimated by means of the maximum likelihood method. Based on the research findings, $75.6 \%$ of the individuals in the sample were willing to pay an amount for the recreational use of the considered resort. The average willingness to pay per person has been determined as 1998.5 rials. When investigating the effective factors, it was determined that the variables of level of suggestion, income, education and household size affect the acceptance of the suggested price for entry into the considered resort. The variables of the level of suggestion and household size have a negative effect and the variables of the level of income and education have a positive effect on the variable of acceptance of the suggested price. Also, the variables of age and gender did not have a significant effect on the acceptance of the suggested price for entry into the aforementioned resort. Based on the findings and results of this study, some suggestions are presented as below:

The income of people is one of the factors effective in willingness to pay for entry into Koohgol resort in Sisakht City; thus, policies must be adopted that lead to the improvement of people's income and reduction of poverty.

- Due to the unique location of Koohgol resort in Sisakht City, in terms of having a very beautiful scenery, favorable climate and also closeness to Sisakht City, this resort can welcome a large number of the enthusiasts of nature; therefore, by proper planning and accurate management, the existing flaws and problems such as shortage of health, welfare and security facilities should be overcome. Also, expansion of sports and recreational facilities, repair and renovation of access ways and creation of proper facilities such as camp will increase the attraction of this resort.

- Based on the estimated recreational value, it is recommended that the public be informed of the various values of this resort so that they will spare no efforts in conserving and maintaining it. 


\section{References}

Amirnezhad, H., (2005). Determination of the total economic value of the ecosystem of the forests in the north of Iran with a focus on environmental-ecological valuation and conservation values, $\mathrm{PhD}$ thesis in Agricultural Economics, Faculty of Agriculture, Teacher Training University.

Amirnezhad, H.; Khalilian, S., (2006). Estimation of the recreational value of the forest parks of Iran using the contingent valuation method: case study of Sisangan forest park in Noshahr, Research and Construction, 59 (2): 365-367.

Parvin, S., (2007). Economic valuation of Hara forest in Hormozgan Province, MS thesis, Shiraz University.

Sameti, M.; Moeeni, Sh.; Mardiha, S. Khanizadeh Amiri, M., (2012). Recreational valuation of Nazhvan forest park in Isfahan using the contingent valuation method, Journal of Applied Ecology, First year, N.1: 64-78.

Moradi, M.; Sadralashrafi, M.; Moghadasi, R.; Yazdani, S., (2012). Estimation of the recreational value of Yasouj forest park using the contingent valuation method, Journal of Studies on Agricultural Economics, Vol. 4, N. 4: 173-190.

Manafi Molayusefi, M.; Hayati, B., (2010). Estimation of recreational value of Maharlou Lake in Shiraz using the contingent valuation method, Iranian Journal of Natural Resources, ISSUE 63, N. 3: Pp. 291-302.

Gurluk, S., 2006. The estimation of ecosystem services value in the region of Misi rural developmentproject: Results from a contingent valuation survey, Journal of Forest Policy and Economics. 9(3): 209- 218.

Lee, C. and Han, S.(2002).Estimating the Use and Preservation Values of National Parks Tourism Resources Using a Contingent Valuation Method, Tourism Management, 23: 531-540.

Lehtonen, E.J., Kuuluvainen, E., Pouta, M., Rekola, and Li, C. (2003).Non-Market Benefits of Forest Conservation in Southern Finland. Environmental Science and Policy, 6: 195-204.

Loomis, j.B., Gonzalez, A.M., Gonzalez-caban, A. (2007).Spatial Limits of the Tcmrevisited: Island Effects. Department of Agricultural and Resource Economics, Colorado state university.

Tietenberg, s. (2003). Environmental and Natural Economics, Sixth Edition,merdith Gertz.

Verbic, M. and Slabe-Erker, R. (2008).An Econometric Analysis of Willingness to Pay for Sustainable Development: a Case Study of the Volcji Potok Landscape Area. Ecological Eeconomics, 66:1-13. 